\title{
Differences in quantitative urine composition in stone-forming versus unaffected mate kidneys
}

This article was published in the following Dove Press journal:

Open Access Journal of Urology

24 August 2009

Number of times this article has been viewed

\author{
Michael L Eisenberg' \\ Keith L Lee' \\ Benjamin N Breyer' \\ Thomas J Walsh² \\ Badrinath R Konety' \\ Marshall L Stoller' \\ 'Department of Urology, University \\ of California San Francisco, San \\ Francisco, CA, USA; ${ }^{2}$ Department \\ of Urology, University of Washington, \\ Seattle, WA, USA
}

Objectives: Many patients present with bilateral stones. There is a unique group of patients, however, that presents with stones exclusively on one side. We hypothesize that in such situations, 24-hour urine collections may not reveal specific defects on the affected stone-bearing kidney. We therefore evaluated selective 12-hour urine collections after percutaneous nephrolithotomy (PNL) to help determine if there is differential renal excretion.

Methods: We collected urine specimens from patients with nephrolithiasis who underwent unilateral PNL. Urine samples were collected and analyzed from nephrostomy tubes, representing the affected kidneys, and from Foley bladder catheters, representing the contralateral mate kidney.

Results: Thirty-one patients were studied (14 with unilateral nephrolithiasis and 17 with bilateral). Treated kidneys from patients with unilateral nephrolithiasis displayed lowered urine excretion of uric acid, sodium, chloride, calcium, and total osmoles when compared to patients with bilateral nephrolithiasis. Stone size and length of procedure were not predictive of urine composition after PNL.

Conclusions: Treated kidneys from patients with a history of unilateral stone disease revealed marked differences in urine excretion compared to those with bilateral nephrolithiasis after unilateral PNL. These findings could be secondary to the surgical insult, urinary stone disease, or could be a responsible factor for stone pathogenesis.

Keywords: percutaneous nephrolithotomy, kidney, stone, nephrolithiasis

\section{Introduction}

Nephrolithiasis affects approximately 7\%-13\% of Americans and cost the US over $\$ 2$ billion in 2000. ${ }^{1}$ Twenty-four-hour urine analysis is the cornerstone of contemporary metabolic stone evaluation, and specific defects including hyperuricosuria, hypercalciuria, hyperoxaluria, and hypocitraturia can be identified and help direct medical management. ${ }^{2}$ However, when voided urine is collected for the 24-hour urine assessment, one assumes symmetric contribution from each renal unit.

Large studies evaluating the efficacy of 24-hour urine collections have shown that $30 \%$ of patients with nephrolithiasis have normal urine electrolytes. ${ }^{3}$ While urolithiasis is felt to be due to systemic metabolic defects, a majority of individuals present with only unilateral nephrolithiasis. ${ }^{4,5}$ In addition, urologists have noted that different unique stone compositions can be found between mate kidneys or that the stone composition in a single kidney can change over time. ${ }^{6}$ Some have surmised that differences in renal perfusion or anatomy have led to such observations. ${ }^{4,5}$
Correspondence: Michael L Eisenberg Department of Urology, University of California San Francisco, 400 Parnassus Ave, UC Clinics A-638, San Francisco, California 94I43-0738, USA

Tel +l 4154766843

Fax +I 4154768849

Email meisenberg@urology.ucsf.edu 
While 24-hour urine analysis assesses global renal excretion, such a collection is unable to differentiate urine production from the right versus left kidney. We hypothesized that differences in urine chemical composition between each renal unit may explain why some individuals develop only unilateral stones. Thus, selective urine collection from each kidney may be useful in identifying differences in urinary compositions between kidneys. ${ }^{7}$

Percutaneous nephrolithotomy (PNL) is used in the management of large upper tract urolithiasis. During postoperative recovery, there is a unique opportunity to explore the real-time differential urine composition between mate kidneys while the nephrostomy tube is actively draining one kidney. In this study of patients undergoing PNL, we collected urine samples over the same time period from both the nephrostomy tube, representing the treated kidney, and the Foley bladder catheter, representing excretion from the contralateral kidney. By comparing urine composition, we sought to determine the acute effects of PNL on urine excretion as well as determine if mate kidneys produce similar urine composition.

\section{Patients and methods}

\section{Patient population}

Between July 2006 and April 2007, we collected urine specimens from patients who underwent unilateral PNL at the University of California San Francisco by a single surgeon (MLS). Patients were excluded if they had a solitary kidney, an intestinal diversion, undergone bilateral PNL, or an improper urine collection. Laterality of stone disease (unilateral versus bilateral), operative time, and stone size were recorded. All patients were evaluated with computed tomography of the abdomen or renal ultrasonography to evaluate for current nephrolithiasis. Stone history reported by patients was correlated with chart review.

\section{Operative technique}

\section{and specimen collection}

PNL was performed using techniques described previously. ${ }^{8}$ Briefly, patients had ureteral exchange catheters placed under cystoscopic guidance. Percutaneous access was obtained by the urologist under fluoroscopic guidance, and the tract was dilated via a Nephromax ${ }^{\mathrm{TM}}$ balloon (Boston Scientific, Natick, MA, USA). Flexible nephroscopy and secondary punctures were utilized when indicated. Following completion of PNL a nephrostomy tube (16 F Foley) was placed in the renal pelvis. The nephrostomy tube, externalized retrograde ureteral exchange catheter in the ipsilateral ureter, and Foley catheter draining the bladder were placed to gravity drainage (Figure 1). The Foley bladder collection represented urine from the untreated mate kidney.

The duration of each procedure, chemical composition of the stone, pre- and postoperative creatinine were collected. After the procedure and recovery in the postoperative unit, urine specimens from the nephrostomy tube and Foley catheter were collected upon arrival on the hospital ward. After a 12-hour urine collection, each specimen was analyzed for sodium, potassium, chloride, calcium, magnesium, phosphate, uric acid, oxalate, osmolarity, $\mathrm{pH}$, protein, and volume. Patients were maintained on intravenous fluids and allowed unrestricted oral intake.

\section{Statistical analysis}

The Mann-Whitney $U$ test was used to determine if a history of bilateral versus unilateral stone disease could predict differences between urine produced by each mate kidney. The Pearson correlation coefficient was utilized to determine the relationship for both stone size and operative

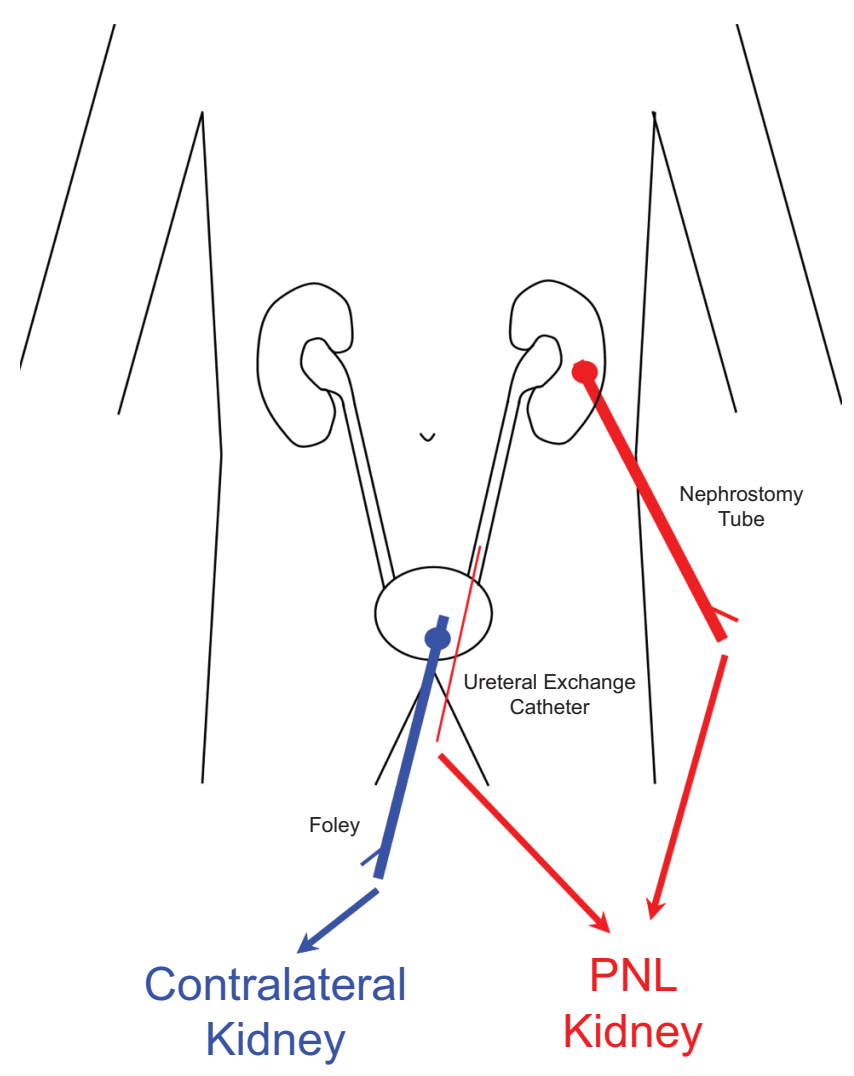

Figure I After PNL, urine from the nephrostomy tube and externalized ureteral stent were collected over 12 hours and combined to represent the affected/operated kidney. Simultaneously, the Foley bladder specimen was collected to represent the contralateral mate kidney.

Abbreviation: PNL, percutaneous nephrolithotomy. 
time. Comparisons between urine variables of the two mate kidneys were made using the Wilcoxon's signed-rank test for paired analyses.

Data analysis was performed utilizing Statview (SAS Institute, Cary, NC, USA). P-values less than or equal to 0.05 were considered statistically significant.

\section{Results}

Thirty-one of 59 (20 female/11 male) patients met inclusion criteria. Patients with a solitary kidney $(n=7)$, an intestinal diversion $(n=5)$, or an improper urine collection $(n=16)$ were excluded. The mean age of patients studied was 53 years (range 24-84 years). Fourteen patients presented with a history of unilateral nephrolithiasis, while 17 patients had a history of bilateral stone disease. The mean case length was 138 minutes (range 54-337 minutes) (Table 1).

Unilateral nephrolithiasis predicted lower excretion of sodium, chloride, calcium, uric acid, and total osmoles after PNL compared to patients with bilateral disease. Neither kidney stone size nor duration of PNL was predictive of impaired concentrating ability in treated kidneys as suggested

Table I Patient demographics and individual case/stone characteristics $(n=3 I)$

\begin{tabular}{|c|c|c|}
\hline $\begin{array}{l}\text { Age: Years } \pm \text { SD } \\
\text { (range) }\end{array}$ & & $\begin{array}{l}52.9 \pm 15.8 \\
(24-84)\end{array}$ \\
\hline \multicolumn{3}{|l|}{ Gender } \\
\hline Female & & 20 \\
\hline Male & & 11 \\
\hline \multicolumn{3}{|l|}{$\begin{array}{l}\text { Laterality } \\
\text { of nephrolithiasis }\end{array}$} \\
\hline Bilateral & & 17 \\
\hline Unilateral & & 14 \\
\hline $\begin{array}{l}\text { Time: minutes } \pm \text { SD } \\
\text { (range) }\end{array}$ & & $\begin{array}{l}138 \pm 60 \\
(54-337)\end{array}$ \\
\hline $\begin{array}{l}\text { Size of stone: } \mathrm{cm} \pm \mathrm{SD} \\
\text { (range) }\end{array}$ & & $\begin{array}{l}2.7 \pm 1.5 \\
(0.5-7)\end{array}$ \\
\hline \multicolumn{3}{|l|}{ Composition of stone: } \\
\hline Number of patients & $\mathrm{Ca} O x$ monohydrate & $21(84)$ \\
\hline with given composition & Hydroxyl apatite & $8(32)$ \\
\hline \multirow[t]{4}{*}{ (\% of total patients) } & Uric acid & $3(32)$ \\
\hline & Carbonate apatite & $2(8)$ \\
\hline & Cystine & I (4) \\
\hline & $\mathrm{Ca}-\mathrm{H} \mathrm{PO} \mathrm{PO}_{4}$ dihydrate & I (4) \\
\hline $\begin{array}{l}\text { Preop creatinine: } \\
\mathrm{mg} / \mathrm{dL} \pm \mathrm{SD} \text { (range) }\end{array}$ & & $\begin{array}{l}0.93 \pm 0.2 \\
(0.6-1.5)\end{array}$ \\
\hline $\begin{array}{l}\text { Postop day \#I creatinine: } \\
\mathrm{mg} / \mathrm{dL} \pm \mathrm{SD} \text { (range) }\end{array}$ & & $\begin{array}{l}1.02 \pm 0.2 \\
(0.7-1.5)\end{array}$ \\
\hline
\end{tabular}

Abbreviation: SD, standard deviation. by a Pearson correlation coefficient between -0.4 and 0.4 (Table 2).

Comparisons between urine specimens collected from the nephrostomy tube/ureteral exchange catheter (representing the treated kidney), and Foley bladder catheter (representing the mate kidney) showed significant differences between all variables analyzed except protein (Figure 2 ). In each case, the Foley bladder specimen was the higher value except in the case of urinary $\mathrm{pH}$ where the nephrostomy sample was significantly elevated (Figure 2).

Creatinine was measured preoperatively (mean $0.93 \mathrm{mg} / \mathrm{dL}$ ) and on postoperative day number 1 (mean $1.02 \mathrm{mg} / \mathrm{dL}$ ) which were not significantly different (Table 1$)$.

\section{Discussion}

For years clinicians have noticed that many patients with nephrolithiasis without evidence of varied anatomy or obstruction present and represent with only unilateral disease..$^{4,5,7}$ In our cohort, 45\% (14/31) of patients had a history of unilateral urolithiasis. No etiology for such stone distribution has been established. A conventional metabolic stone evaluation involves urine and serum electrolyte studies which reflect systemic conditions. Yet in unilateral urolithiasis such studies seem unsatisfying and may be unable to unmask the true etiology of recurrent unilateral stone disease.

Groups have postulated explanations: anatomy, renal blood flow, sleep posture, varied urine electrolytes between kidneys, etc. ${ }^{4,5,7,9}$ Yet to date, no data exists comparing

Table 2 Analysis of 12-hour urine collections from the treated kidneys using preoperative variables (procedure time, stone size, laterality of stone disease)

\begin{tabular}{llll}
\hline Variable & $\begin{array}{l}\text { Procedure }^{\text {time }}{ }^{\dagger} \text { (Pearson } \\
\text { coefficient) }\end{array}$ & $\begin{array}{l}\text { Stone size }^{\dagger} \\
\text { Pearson }^{\dagger}\end{array}$ & $\begin{array}{l}\text { Laterality of } \\
\text { stone disease }\end{array}$ \\
\hline Calcium & -0.03 & -0.06 & $\mathbf{0 . 0 4 ^ { * }}$ \\
Chloride & 0.24 & 0.10 & $\mathbf{0 . 0 5 ^ { * }}$ \\
Magnesium & 0.32 & 0.35 & 0.09 \\
Osmoles & 0.06 & 0.01 & $\mathbf{0 . 0 5}$ \\
pH & -0.09 & -0.03 & 0.12 \\
Phosphate & 0.38 & 0.05 & 0.26 \\
Potassium & 0.16 & 0.16 & 0.13 \\
Protein & -0.08 & -0.13 & 0.19 \\
Sodium & 0.35 & 0.16 & $\mathbf{0 . 0 5}$ \\
Uric acid & 0.16 & 0.08 & $\mathbf{0 . 0 5}$ \\
Volume & 0.00 & -0.01 & 0.16 \\
\hline Notes: & & &
\end{tabular}

Notes: ${ }^{\dagger}$ Analyses performed using linear regression with Pearson coefficient listed. ${ }^{\ddagger}$ Analyses performed using Mann-Whitney test with $\mathrm{p}$ values listed. *Values noted in patients with bilateral nephrolithiasis. 


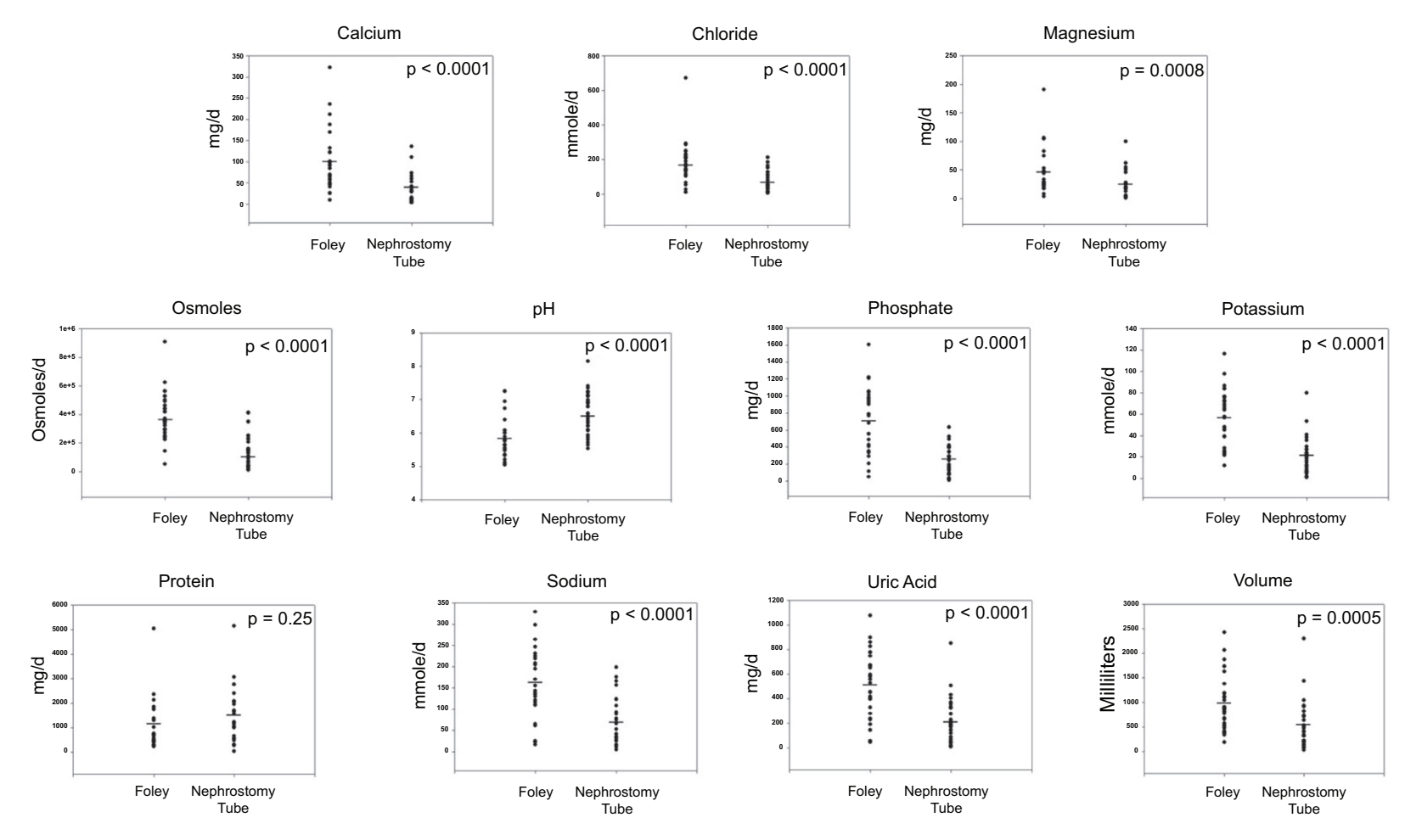

Figure 2 Scatterplot comparison of urine composition between bladder Foley and nephrostomy/externalized ureteral specimens. Horizontal bar represents mean value of given parameter. Analysis was performed using Wilcoxon's signed-rank test; $\mathrm{p}$ value listed.

excretory renal function between patients with unilateral and bilateral stone disease. The lungs provide and ideal example of a paired organ system where variations in anatomy, position, and perfusion have profound effects on mate pulmonary function and underlying pathology. ${ }^{10}$ It seems logical that such factors could be at play in kidney physiology.

To our knowledge, this is the first study to show a difference in renal excretion between patients with unilateral and bilateral nephrolithiasis. Patients with unilateral nephrolithiasis displayed impaired excretion of uric acid, sodium, chloride, calcium, and total osmoles from the stone-bearing kidney compared to patients with a history of bilateral nephrolithiais, suggesting a greater susceptibility to renal impairment after PNL. Such differences likely existed prior to percutaneous intervention and may have been caused by the chronic insult of nephrolithiasis itself or prior interventions. None of the 12 variables analyzed displayed impaired excretion in patients with a history of bilateral nephrolithiasis. It is unclear if the chronic stone disease led to these electrolyte differences, or, in contrast, whether these electrolyte differences were, indeed, responsible for the development of urolithiasis.

Longer follow up is necessary to determine if patients with unilateral nephrolithiasis are at an increased risk of renal impairment after PNL. Perhaps observation rather than intervention may be indicated for asymptomatic stones in such patients.

PNL provides a unique opportunity to explore individual renal function and compare excretory renal function between mate kidneys. In our model, the mate kidney functioned as an ideal control for the treated kidney. Each kidney was exposed to identical hydration, anesthetic, hemodynamics, position, and medication conditions. In fact, Handa and colleagues explored a porcine model to study the acute effects of PNL and found a decline in renal function of control animals, which suggests that anesthesia and/or the semiprone position alone may impair renal function. ${ }^{11}$ In addition, as perfusion plays a key role in renal function, an analysis of the effect of PNL on quadripeds may not accurately mirror human patients.

The trauma of puncture, dilatation, and lithotripsy may alter renal function hampering comparison between mate kidneys and leading to lower electrolyte excretion in the treated kidney. When evaluating treated kidneys, we noted dramatic impairment of electrolyte excretion in patients with unilateral nephrolithiasis when compared to those with bilateral disease. If such an analysis were possible as an outpatient, such results may be more insightful when the patient consumes a normal diet. However, as of yet, there is no noninvasive method for such analysis. 
Twenty-four-hour urinalyses remain a standard tool for the evaluation of nephrolithiasis. Yet up to one-third of 24-hour urinalyses fail to yield a metabolic abnormality thought to be responsible for urolithiasis. ${ }^{3,12}$ In fact, patients with a single stone occurrence have a similar number of metabolic abnormalities as those with multiple stones or no stones. ${ }^{3,13}$ Conversely, many individuals with abnormal 24-hour urinalyses will never form calculi. ${ }^{14,15}$

Our study compared the urine produced by each kidney and found that differences can exist between mate kidneys. Across nearly all variables studied, the urine composition between the nephrostomy tube and Foley bladder catheter differed between mate kidneys suggesting variability in the handling of ion excretion. Our study suggests that traditional 24-hour urinalysis, which represents pooled urine from both kidneys, may not accurately represent metabolic derangements in individual kidneys. Hypersecreters of stone-forming elements or hyposecreters of stone inhibitors in those with unilateral nephrolithiasis may be masked. Alternative ambulatory-centered methods before and after surgery may be needed to explore the urine composition of the individual kidneys in those with nephrolithiasis.

A weakness of our study involves our method of collection between the two mate kidneys. While the nephrostomy tube certainly contains urine from only one kidney, the Foley bladder catheter, which we collected as an indicator of urine from the contralateral kidney, may contain "contaminated" urine from both kidneys. While this flaw would be expected to lessen the differences between kidneys, we still found large differences in urine composition. Other groups have reported complete collection via a ureteral exchange catheter with no urine escaping around the catheter and pooling in the bladder. ${ }^{7}$ In addition, tiny residual stone fragments in the treated kidney could contaminate the urine collected in the postoperative period.

\section{Conclusions}

Quantitative urine collection from individual kidneys after PNL revealed marked differences in urinary electrolyte excretion in patients presenting with unilateral stone disease. Such findings may give insight into the etiology of unilateral nephrolithiasis or alternatively may be the result of the stone disease itself. Urine collection of patients with bilateral nephrostomy tubes placed for supravesical diversion is currently ongoing to explore handling of electrolytes between mate kidneys in the chronic setting.

\section{Disclosures}

The authors report no conflicts of interest in this work.

\section{References}

1. Pearle MS, Calhoun EA, Curhan GC. Urologic diseases in America project: urolithiasis. J Urol. 2005;173(3):848-857.

2. Moe OW. Kidney stones: pathophysiology and medical management Lancet. 2006;367(9507):333-344.

3. Trinchieri A, Ostini F, Nespoli R, Rovera F, Montanari E, Zanetti G. A prospective study of recurrence rate and risk factors for recurrence after a first renal stone. J Urol. 1999;162(1):27-30.

4. Purohit RS, Stoller ML. Laterality of symptomatic cystine calculi. Urology. 2003;62(3):421-424.

5. Shekarriz B, Lu HF, Stoller ML. Correlation of unilateral urolithiasis with sleep posture. J Urol. 2001;165(4):1085-1087.

6. Evan AP, Coe FL, Lingeman JE, Worcester E. Insights on the pathology of kidney stone formation. Urol Res. 2005;33(5):383-389.

7. Malek RS, Wilkiemeyer RM, Boyce WH. The stone-forming kidney: a study of functional differences between individual kidneys in idiopathic renal lithiasis. J Urol. 1976;116(1):11-14.

8. Stoller ML, Wolf JS Jr, St Lezin MA. Estimated blood loss and transfusion rates associated with percutaneous nephrolithotomy. $J$ Urol. 1994;152(6 Pt 1):1977-1981.

9. Higashihara E, Nutahara K, Tago K, Ueno A, Niijima T. Unilateral and segmental medullary sponge kidney: renal function and calcium excretion. J Urol. 1984;132(4):743-745.

10. Johansson MJ, Wiklund A, Flatebo T, Nicolaysen A, Nicolaysen G, Walther SM. Positive end-expiratory pressure affects regional redistribution of ventilation differently in prone and supine sheep. Crit Care Med. 2004;32(10):2039-2044.

11. Handa RK, Matlaga BR, Connors BA, et al. Acute effects of percutaneous tract dilation on renal function and structure. $J$ Endourol. 2006;20(12):1030-1040.

12. Strauss AL, Coe FL, Parks JH. Formation of a single calcium stone of renal origin. Clinical and laboratory characteristics of patients. Arch Intern Med. 1982;142(3):504-507.

13. Pak CY. Should patients with single renal stone occurrence undergo diagnostic evaluation? J Urol. 1982;127(5):855-858.

14. Asplin JR, Lingeman J, Kahnoski R, Mardis H, Parks JH, Coe FL. Metabolic urinary correlates of calcium oxalate dihydrate in renal stones. J Urol. 1998;159(3):664-668.

15. Curhan GC, Willett WC, Speizer FE, Stampfer MJ. Twenty-four-hour urine chemistries and the risk of kidney stones among women and men. Kidney Int. 2001;59(6):2290-2298.
Open Access Journal of Urology

\section{Publish your work in this journal}

The Open Access Journal of Urology is an international, peer-reviewed, open access journal publishing original research, reports, editorials, reviews and commentaries on all aspects of adult and pediatric urology in the clinic and laboratory including the following topics: Pathology, pathophysiology of urological disease; Investigation and treatment of

\section{Dovepress}

urological disease; Pharmacology of drugs used for the treatment of urological disease. The manuscript management system is completely online and includes a very quick and fair peer-review system, which is all easy to use. Visit http://www.dovepress.com/testimonials.php to read real quotes from published authors. 